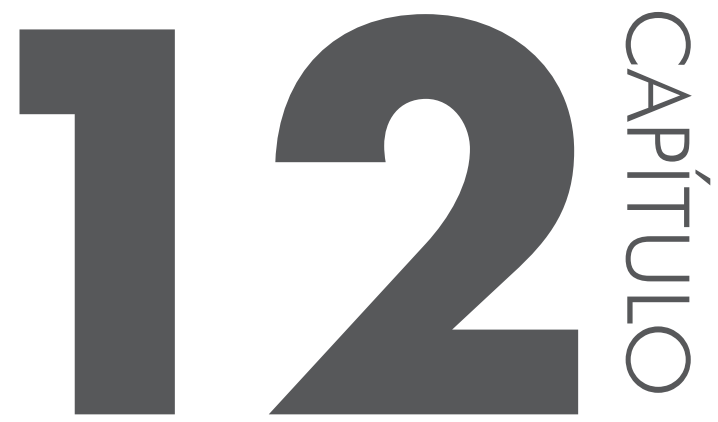

\title{
GERMINAC̣ÃO E DESENVOLVIMENTO IN VITRO DE BRASSAVOLA TUBERCULATA HOOK
}

Matteus Miranda Reis ${ }^{1}$ Maria Rita de Cássia Campos ${ }^{1}$

Agradecimentos: Ao Programa Institucional de Iniciação Científica pela seleção do aluno como PIVIC.

Resumo: Este trabalho teve como objetivo analisar o estabelecimento in vitro inicial de Brassavola tuberculata por meio de semeadura assimbiótica, visando sua conservação in vitro. As sementes $(10 \mathrm{mg})$ foram desinfestadas por meio de

1 Unidade Acadêmica Especial de Biotecnologia, Universidade Federal de Goiás - Regional Catalão, Catalão, Brasil.

E-mail: matteus_miranda@hotmail.com,campos.mariarita@yahoo.com.br 
solução de $\mathrm{NaOCl} 10 \%$ por 15 minutos sobre agitação. Em seguida, foram lavadas por duas vezes em água destilada e autoclavada. Após a assepsia, as sementes foram inoculadas em 20 frascos de $200 \mathrm{~mL}$ contendo $30 \mathrm{~mL}$ de meio B\&G ${ }^{\circ}$. Dos recipientes, 10 foram mantidos em ambiente sem iluminação e 10 em sala de crescimento com temperatura de $25 \pm 2{ }^{\circ} \mathrm{C}$ para ambos os tratamentos. O delineamento experimental foi totalmente casualizado, com dois tratamentos e dez repetições, sendo cada repetição um frasco. Inicialmente, notou-se contaminação por fungos nos dois tratamentos. Após 15 dias da inoculação, verificou-se que as sementes apresentaram-se intumescidas, mostrando a formação de protocormos aos 30 dias da inoculação. Em 45 dias ocorreu o surgimento de estruturas aéreas. Em 120 dias, plântulas foram observadas em ambos tratamentos, sendo observada raiz nas que se encontravam no escuro. O estabelecimento in vitro de $B$. tuberculata pode ser efetuado por meio da germinação in vitro e, logo após a semeadura assimbiótica, as sementes de orquídeas devem ser mantidas no escuro.

Palavras-chave: Cultura de tecidos. B. tuberculata. Germinação in vitro.

Abstract: This study was aimed to analyse the initial establishment in vitro of Brassavola tuberculata through the nonsymbiotic cultivation, bearing in mind the conservation of in vitro. The seeds $(10 \mathrm{mg})$ were sterilized by $\mathrm{NaOCl}$ $10 \%$ solution and stirred for 15 minutes, then washed twice in distilled water and autoclaved. After sterilization, seeds were inoculated in 20 flasks of $200 \mathrm{~mL}$ containing $30 \mathrm{~mL}$ of medium $B \& G^{\circledR} .10$ recipients were kept in a dark room, and 10 in a growth room with temperature $25 \pm 2{ }^{\circ} \mathrm{C}$ for both treatments. The experimental design was completely randomized with two treatments and ten repetitions, each repetition used by a flask. Initially, fungal contamination was noted in both treatments. After 15 days from inoculation, it was found that the seeds had swollen up, showing the formation of protocorm 30 days after inoculation. After 45 days, there was the emergence of overhead structures. On the $120^{\text {th }}$ day seedlings were observed in both treatments, on the roots that were in the dark. The establishment of in vitro B. tuberculata can be accomplished through in vitro germination and soon after nonsymbiotic, cultivating the seeds of orchids should be kept in the dark.

Keywords: Tissue culture. B. tuberculata. Germination in vitro.

\section{INTRODUC̣ÃO}

\subsection{Biologia das orquídeas}

As orquídeas são plantas herbáceas perenes diversificadas quanto ao tamanho, à forma dos caules, às folhas e à cor das flores (SCHNEIDER et al., 2012). Estas plantas pertencem à família Orchidaceae e à ordem Asparagales, correspon- 
dendo à maior família dentre as Angiospermas. Possuem cerca de 850 gêneros e 20.000 espécies no mundo, sendo que no Brasil, podem ser encontrados cerca de 236 gêneros e 2.430 espécies (APG III, 2009). Embora a diversidade de orquídeas seja alta no Brasil e em diversas partes do mundo, muitas espécies são vítimas de extrativismo, levando muita das vezes à sua extinção (VENDRAME et al., 2014).

A família Orchidaceae é constituída de grande número de gêneros, espécies e híbridos e, dentre os principais gêneros encontrados no Brasil, destaca-se o gênero Brassavola. (FARIA et al., 2012). A espécie Brassavola sp. é conhecida popularmente como chuva de prata, cebolinha, rabo de rato e orquidea dama-da-noite. Esta espécie possui elevado valor ornamental, pois além da sua rusticidade, apresenta floração bastante abundante e duradoura, produzindo inflorescências com cinco a sete flores de coloração branca levemente amarelada, que exalam odor levemente adocicado ao anoitecer (RECH; ROSA; MANENTE-BALESTIERI, 2010). Além disso, Brassavola sp. é importante economicamente por originar híbridos do intercruzamento com Cattleya, Laelia, Sophronitis e Epidendrum (SOARES et al., 2012).

Devido a essas características, a coleta predatória deste gênero em seu habitat se torna mais frequente (HERING; PUTZKE, 2007). A espécie Brassavola tuberculata é nativa dos estados de Alagoas, Bahia, Minas Gerais, Paraíba, Paraná, Pernambuco, Rio Grande do Sul, Santa Catarina, São Paulo, Sergipe e Tocantins (BARROS et al., 2013) ocorrendo também no Mato Grosso do Sul (RECH; ROSA; ROSA-JUNIOR, 2010).

\subsection{Conservação in vitro}

O extrativismo e a destruição de habitats naturais vêm levando espécies endêmicas a entrar em extinção, tornando-se necessárias técnicas de conservação in vitro. Uma forma de manter não só a integridade genética dos estoques, mas também parte da diversidade genética das espécies é por meio da conservação do germoplasma in vitro (VIEIRA et al., 2001; PINHAL et al., 2011).

A conservação in vitro é importante por permitir o resgate de populações que correm o risco de extinção, preservação da diversidade genética, intercâmbio de plântulas entre centros de pesquisas e redução das perdas causadas por desastres naturais. Além disso, segundo Santos et al. (2011) e Reed, Gupta e Uchendu (2013), a preservação de germoplasma in vitro apresenta, em médio prazo, um baixo custo econômico e algumas vantagens em comparação com a conservação no campo, como a redução do espaço de armazenamento e a rápida multiplicação de material vegetal livre de pragas e patógenos presentes no campo.

A cultura de tecidos pode contribuir tanto para a fase de conservação como de avaliação dos acessos, coleções de trabalho e bancos de germoplasma (MAN- 
TELL; MATTHEWS; MCKEE, 1994). Outra finalidade importante da cultura de tecidos é facilitar a produção em larga escala de espécies de propagação vegetativa de importância econômica a partir de um único explante, permitindo a conservação do genótipo através do desenvolvimento de duas tecnologias integradas: a micropropagação e o estabelecimento de banco de germoplasma in vitro, que são complementares aos bancos de sementes, como é feito rotineiramente para culturas como a banana, batata, cana-de-açúcar, entre outras (SANTOS, 2000; SANTOS; SALOMÃO, 2010; MORAES et al., 2007). No entanto, a manutenção das culturas in vitro necessita de subcultivos periódicos e podem ocorrer perdas por contaminação, existindo também a possibilidade de variação genética ao longo do cultivo que comprometem o desenvolvimento da cultura (SOUZA et al., 2007).

\subsection{Cultivo in vitro}

O cultivo in vitro é uma técnica que, segundo Mantell, Matthews e McKee (1994), permite que pequenos fragmentos de tecido vivo (explante) sejam isolados de um organismo e cultivado assepticamente por períodos indeterminados em um meio nutritivo semidefinido ou definido. A partir dessa descoberta, com a obtenção dos conhecimentos sobre a atuação dos principais hormônios vegetais (auxinas e citocininas) e seus efeitos no crescimento e divisão celular nas plantas, foi demonstrado que explantes de tecidos vegetais podiam se proliferar através de repetidas divisões celulares e quando as condições de cultura apropriadas eram proporcionadas, massas celulares podiam então seguir através de várias vias metabólicas de desenvolvimento e assim regenerar brotos, raízes e, eventualmente, plantas inteiras.

Com base nas técnicas de cultivo in vitro e na necessidade de resgate das populações de alguns grupos de plantas, tais técnicas podem ser usadas para a preservação de orquídeas. As espécies mantidas em laboratório apresentam, segundo Altafin et al. (2002), um alto vigor fisiológico, em virtude de sua nutrição balanceada nas fases iniciais de desenvolvimento, e isto se traduz em rápido crescimento e maior tolerância a condições adversas de meio ambiente, bem como ao ataque de doenças e pragas, além do manuseio de grande número de indivíduos em espaço reduzido e sob condições assépticas (UNEMOTO et al., 2007).

\subsection{Germinação ao desenvolvimento inicial}

Em orquídeas a germinação in vitro se inicia com expansão dos embriões dando origem a uma estrutura cônica. Conceitos relacionados à germinação, em 
sementes de orquídeas, variam entre autores. Harvais (1973) considera que a semente germinou quando o embrião demonstra indício de atividade, por outro lado, outros autores consideram germinadas as sementes após o rompimento pelo embrião (KAUTH et al., 2006), e outros ainda a consideram germinada somente após a gema caulinar estar diferenciada (CURTIS; NICHOL, 1948; ICHIHASHI, 1990). No processo de germinação de sementes em orquídeas, o embrião desenvolve em uma estrutura denominada protocormo (LEROUX; BARABÉ; VIETH, 1995; JOHNSON; KANE; PÉREZ, 2011). O protocormo passa por fases de diferenciação de tecidos e órgãos, originando folhas e raízes adventícias sendo então denominado plântula (BARABÉ; SAINT-ARNAUD; LAUZER, 1993). Existe uma variação no tempo entre a semeadura assimbiótica e a formação da plântula dependendo da espécie e das condições de cultivo.

Em ambiente natural, orquídeas apresentam crescimento lento e precisam de interação simbiótica com fungos (KALIMUTHU; SENTHILKUMAR; VILAYAKUMAR, 2007). No ambiente de laboratório, as orquídeas apresentam alta porcentagem de germinação sem que as sementes precisem desta relação simbiótica. A cultura de tecidos facilita a propagação em larga escala de espécies de importância econômica e, a partir de um único explante, permite a conservação do genótipo através do desenvolvimento de duas tecnologias integradas, a micropropagação e o estabelecimento de banco de germoplasma in vitro (MORAES et al., 2007).

Todas as fases do crescimento e desenvolvimento in vitro são influenciadas por presença, intensidade e qualidade da luz. Além disso, o fotoperíodo é imprescindível para adaptação dos explantes em condições in vitro (ICHIHASHI, 1990; JOHNSON; KANE; PÉREZ, 2011).

O objetivo deste trabalho foi analisar o estabelecimento in vitro inicial por meio da semeadura assimbiótica da espécie Brassavola tuberculara Hook, visando a conservação in vitro desta espécie.

\section{MATERIAIS}

O trabalho foi realizado no Laboratório de Ciências Morfológicas e Biodiagnóstico (LaMorBio) da Universidade Federal de Goiás (UFG) - Regional Catalão.

\subsection{Material vegetal}

Cápsulas fechadas (Figura 1A) contendo as sementes (Figura 1B) de B. tuberculata foram obtidas a partir de indivíduos selecionados (Figura 1C) da coleção de Dionatas Gonçalves Ribeiro, Catalão, Goiás. 


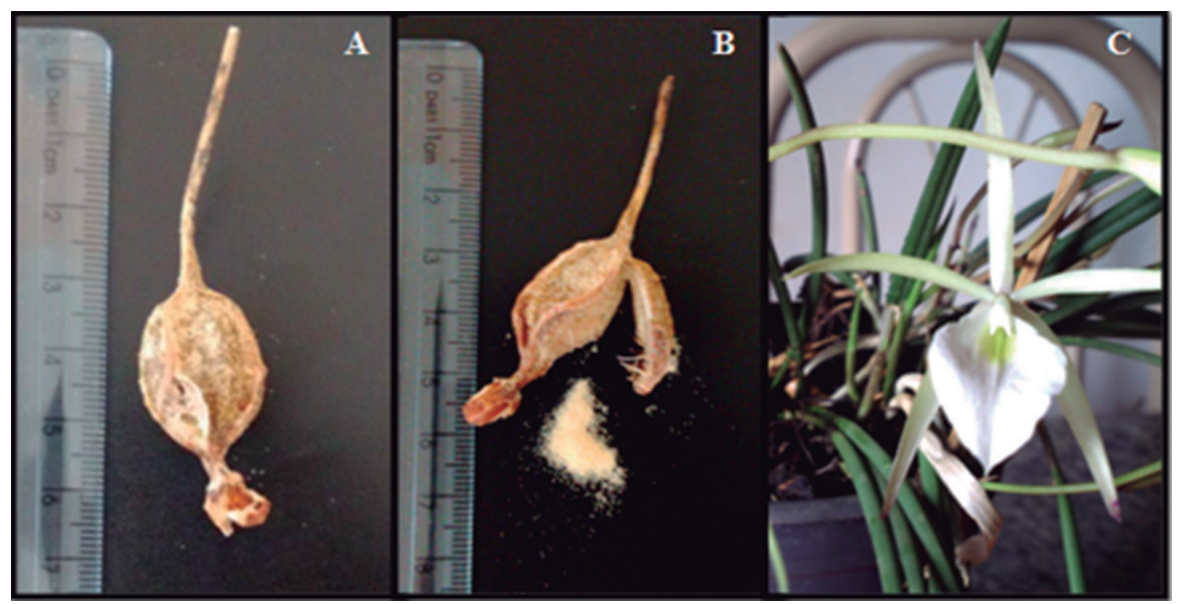

Figura 1. Detalhes de B. tuberculata. A) Cápsula fechada; B) cápsula aberta mostrando sementes (seta); C) flor.

\subsection{Desinfestação e inoculação in vitro}

Em câmara de fluxo laminar, as sementes $(10 \mathrm{mg})$ foram submetidas à desinfestação por meio da solução de $\mathrm{NaOCl} 10 \%$ por 15 minutos sobre agitação utilizando uma seringa estéril. A seguir foram efetuadas duas lavagens em água destilada e autoclavada. Após a assepsia, as sementes foram inoculadas em 20 frascos de vidro com capacidade de $280 \mathrm{~mL}$ contendo $30 \mathrm{~mL}$ de meio $B \& \mathrm{G}^{\circledR}$, $10 \mathrm{gL}^{-1}$ de ágar e $\mathrm{pH}$ ajustado para 5,8 $\pm 0,2$ antes da esterilização em autoclave a $120^{\circ} \mathrm{C}$ e à pressão de $1,05 \mathrm{~kg} / \mathrm{cm}^{2}$ por 20 minutos. Após a inoculação, 10 frascos contendo os explantes foram mantidos por 15 dias no ambiente sem iluminação e 10 frascos foram mantidos em sala de crescimento com irradiância em torno de $35 \mathrm{mmolm}^{-2} \mathrm{~s}^{-1}$, temperatura de $25 \pm 2{ }^{\circ} \mathrm{C}$.

\subsection{Delineamento experimental}

O delineamento experimental utilizado foi o inteiramente casualizado com dois tratamentos e dez repetições, cada uma representada por um frasco com $10 \mathrm{mg}$ de sementes distribuídas aleatoriamente. As avaliações foram realizadas, inicialmente a cada dois dias para verificar as possíveis contaminações. Quinze dias após a inoculação das sementes, os frascos mantidos em ambiente sem iluminação foram transferidos para ambiente com irradiação. Foram feitas análises semanais do desenvolvimento inicial in vitro. Foram consideradas sementes germinadas aquelas que apresentavam intumescimento do embrião $\mathrm{O}$ início do desenvolvimento foi marcado com o surgimento de protocormos. Foi considerada plântula após surgimento da parte aérea. 


\section{RESULTADOS E DISCUSSÃO}

$\mathrm{Na}$ análise inicial, foi observada contaminação microbiana nos primeiros dias após inoculação das sementes, independente da presença ou da ausência de luz. Neste trabalho observou-se, inicialmente, contaminação por fungos (Figuras $2 \mathrm{~A}$ e $2 \mathrm{~B}$ ) em $40 \%$ dos frascos mantidos no escuro e $20 \%$ dos frascos mantidos na luminosidade. A partir da observação do fungo, foi feita a coleta do mesmo com fita adesiva e esta foi colocada sobre uma lâmina contendo corante para obtenção da imagem observada ao microscópio na Figura 2B.

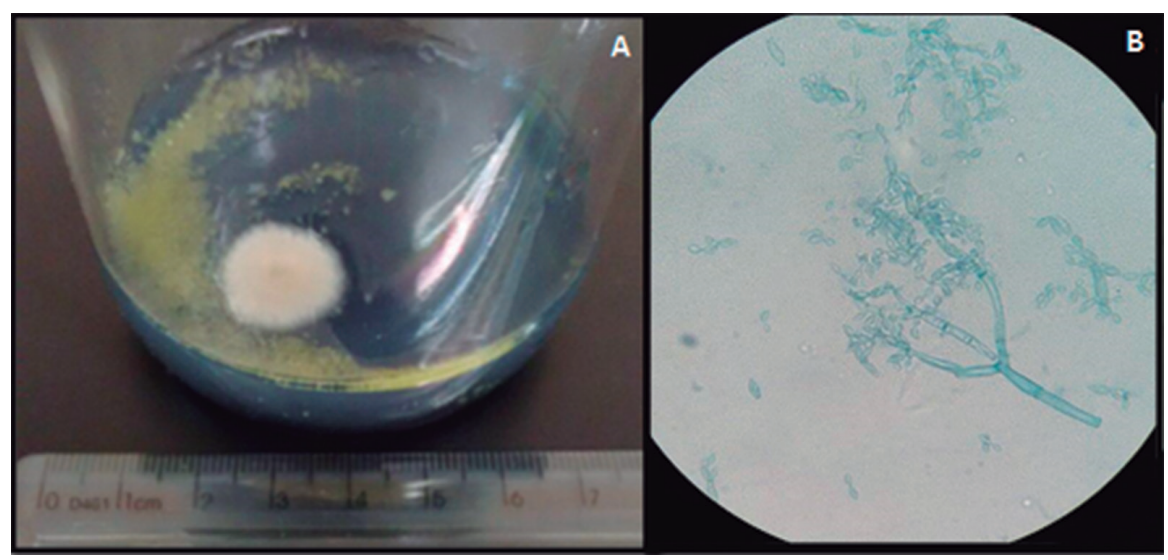

Figura 2. A) Contaminação do meio de cultura por fungo; B) hifas e esporos de fungos em microscopia de luz em aumento de 1.000x.

As possíveis causas de contaminação podem estar relacionadas ao manuseio dos recipientes no laboratório, descuidando-se das práticas assépticas necessárias para a manipulação das culturas (THOMAS; SOLY, 2009; THOMAS; KUMARI 2010). Mesmo com cuidados com assepsia, em biofábricas brasileiras já foram registradas porcentagens de contaminação superiores a 30\% causadas tanto por fungos como por bactérias (NIETSCHE et al., 2006; SOUZA et al., 2007).

O início da germinação das sementes de $B$. tuberculata foi verificado cerca de quinze dias após a inoculação no meio de cultura. Observou-se o intumescimento do embrião e o rompimento da testa, formando um corpo globular esverdeado e indicando a presença de clorofila. No presente trabalho, inicialmente houve intumescimento das sementes, independentemente da fonte luminosa (Figsuras 3A e 3B), levando ao rompimento do tegumento seminal e à liberação do embrião, com diferenças na coloração em função da exposição à luz.

O processo inicial do desenvolvimento in vitro considerado neste trabalho foi a fase de protocormo, pois nas descrições de Kraus, Kerbauy e Monteiro (2006) e Arditti (2008), o padrão de germinação de sementes de orquídeas é uniforme; ou seja, as sementes começam a intumescer. 


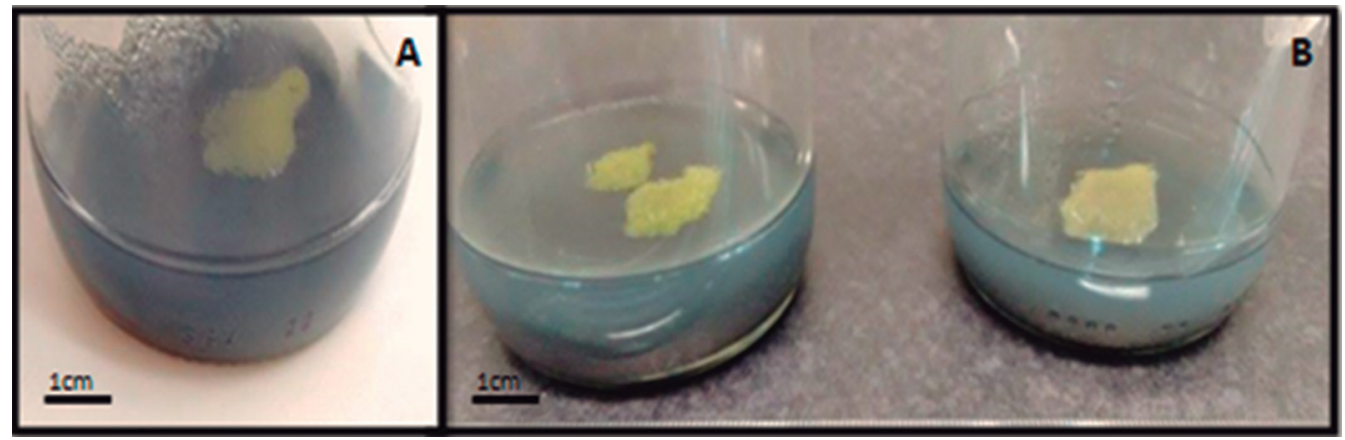

Figura 3. Intumescimento das sementes em ambos os tratamentos. A) 12 dias após a inoculação das sementes no tratamento com iluminação; B) 20 dias após a inoculação das sementes nos dois tratamentos.

O embrião se desenvolveu numa estrutura tuberiforme, como foi verificado neste estudo, chamada de protocormo (Figuras 4A e 4B). As estruturas observadas apresentam aspecto esverdeado, nas quais a região mais afilada e basal mais globosa, tuberculiforme, já podem ser claramente reconhecidas, caracterizando o protocormo.

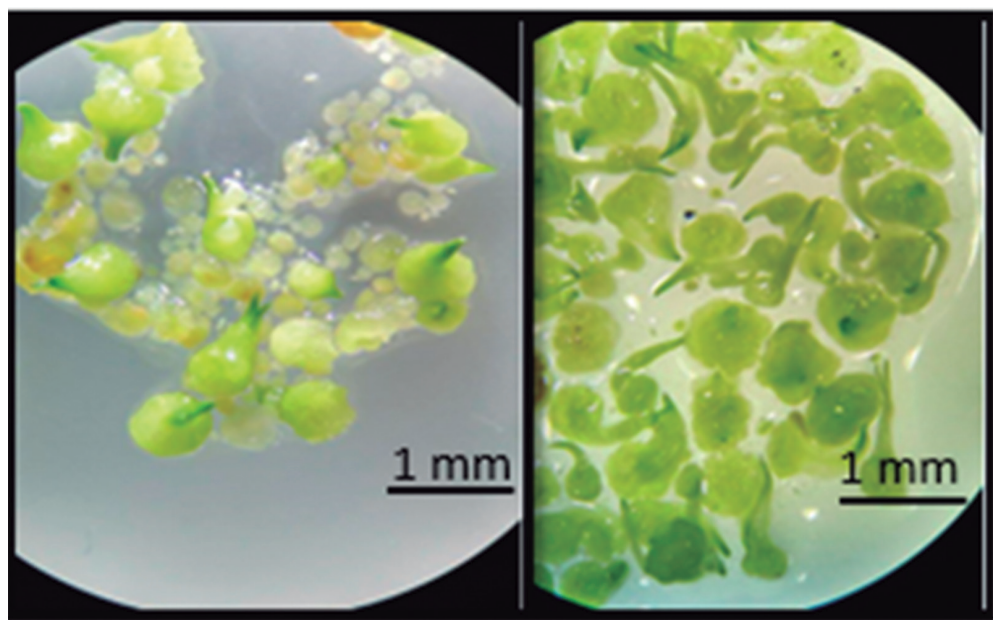

Figura 4. Surgimento dos protocormos após 30 dias de inoculação. A) Tratamento com luminosidade; B) tratamento sem luminosidade.

Em relação ao tempo de germinação, há variação na literatura relacionada ao genótipo. Sementes de Cattleya bicolor Lindl. mostraram protocormos após 20 dias da inoculação (SANTOS et al., 2007), as sementes de C. forbesii germinaram aos 30 dias após a semeadura, independentemente do tratamento (SCHNEIDERS et al., 2012). Para Oncidium flexuosum Sims, Pereira et al. (2005) observaram $90 \%$ de germinação aos 7 dias após a inoculação das sementes. As sementes 
de $B$. tuberculata germinaram aos 30 dias após a semeadura, independentemente do tratamento (luz e escuro) (Tabela 1), tendo o ambiente escuro promovido a maior taxa de germinação das sementes em comparação com o claro, $78 \% \pm 11,5$ e $66 \% \pm 6,55$, respectivamente.

Tabela 1. Taxa de germinação de sementes de $B$. tuberculata obtida trinta dias após a semeadura in vitro

\begin{tabular}{cc}
\hline Condições experimentais & Germinabilidade (\%) \pm DP \\
\hline Luz & $66 \pm 6,55$ \\
Escuro & $78 \pm 11,5$ \\
\hline
\end{tabular}

Após 120 dias em sala de crescimento, verificou-se o desenvolvimento das plântulas mantidas em ambiente sem iluminação (Figura 5A). As plântulas mantidas em claro apresentaram o desenvolvimento da parte aérea sem a presença de raízes (Figura 5B). Schneiders et al. (2012) observaram que os protocormos se desenvolveram em plântulas após 180 dias da inoculação das sementes em Cattleya forbesii.

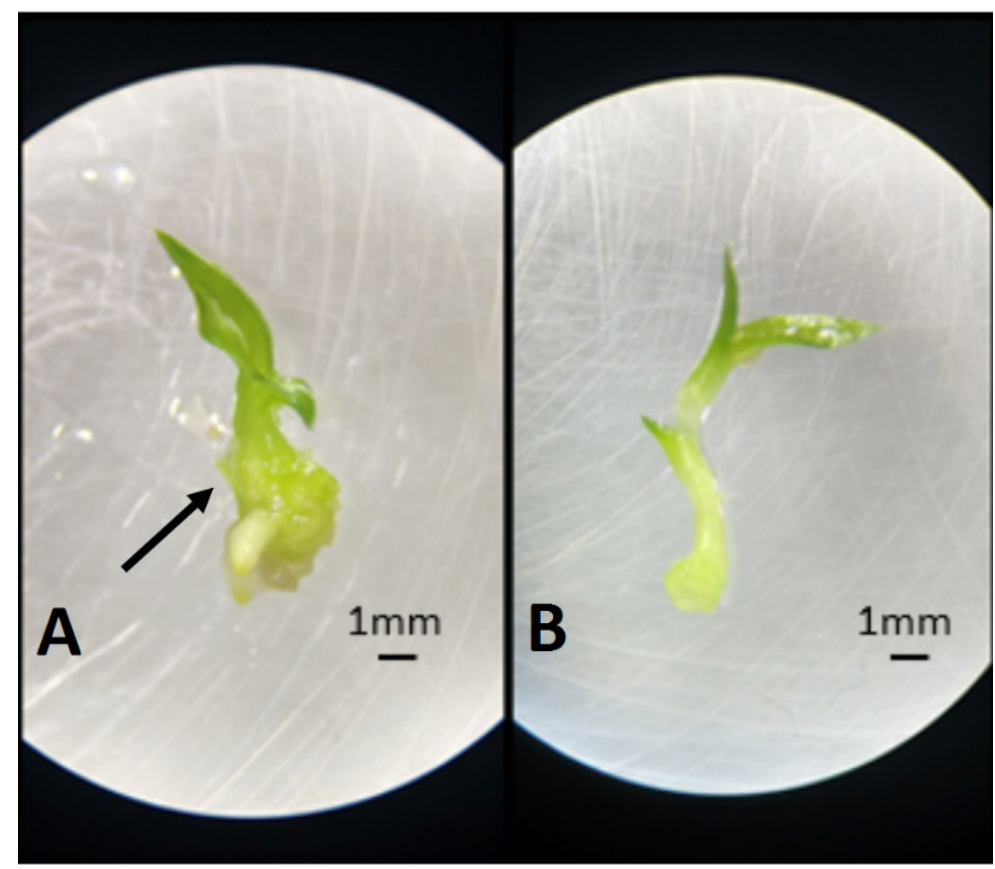

Figura 5. Comparação de plântulas que se desenvolveram em ambos tratamentos. A) Tratamento sem iluminação (raiz indicada pela seta); B) tratamento com iluminação. 
Com base nos resultados obtidos neste trabalho com plantas de B. tuberculata, na presença e ausência de luz, observou-se que ocorrem padrões distintos quando os explantes foram incubados na ausência de luz. Desta forma, recomenda-se a utilização do ambiente escuro para a germinação das sementes e o crescimento inicial de B. tuberculata.

\section{CONCLUSÃO}

A germinação das sementes e o crescimento inicial de $B$. tuberculata mostrou melhores resultados na ausência de luz. Considerando as condições experimentais utilizadas no presente estudo, os resultados obtidos apontaram para aspectos que poderão ser utilizados como subsídios para continuação da atual abordagem experimental, cuja compreensão, sob o ponto de vista de aplicabilidade, poderá auxiliar no desenvolvimento de protocolos para conservação in vitro de plantas em vias de extinção ou de interesse comercial.

\section{REFERÊNCIAS}

ALTAFIN, V. L.; MENEZES, M. O.; LIMA FILHO, R. R.; PITOMBO, L. M.

Semeadura in vitro de orquídeas para propagação massal. Espírito Santo do Pinhal: CREUPI, 2002.

APG III. An update of the Angiosperm Phylogeny Group classification for the orders and families of flowering plants: APG III. Botanical Journal of the Linnean Society, 161, 105-121, 2009.

ARDITTI, J. Micropropagation of orchids. 2. ed. Melbourne: Blackwell Publishing, 2008. BARABÉ, D.; SAINT-ARNAUD, M.; LAUZER, D. Sur la nature des protocormes d'Orchidées (Orchidaceae). Comptes Rendus de l'Académie des Sciences, v. 316, p. 139144, 1993.

BARROS, F.; VINHOS, F.; RODRIGUES, V. T.; BARBERENA, F. F. V. A.; FRAGA, C. N.; PESSOA, E. M.; FORSTER, W.; MENINI NETO, L.; FURTADO, S. G.; NARDY, C.; AZEVEDO, C. O.; GUIMARÃES, L. R. S. Orchidaceae in lista de espécies da flora do Brasil. Jardim Botânico do Rio de Janeiro. Disponível em: <http://floradobrasil.jbrj. gov.br/jabot/floradobrasil/fb11230>. Acesso em: 1 mai. 2015.

CURTIS, J. T.; NICHOL, M. A. Culture of proliferation orchid embryos in vitro.

Bulletin of the Torrey Botanical Club., v. 75, p. 358-373, 1948.

ENGELMANN, F. Use of biotechnologies and conservation of plant biodiversity. In vitro Cellular \& Developmental Biology - Plant, v. 45, p. 5-16, 2011.

FARIA, R. T.; ASSIS, A. M.; UNEMOTO, L. K.; CARVALHO, J. F. R. P. Produção de orquídeas em laboratório. Londrina: Mecenas, 2012.

HARVAIS, G. Growth requirements and development of Cypridium reginae in axenic culture. Canadian Journal of Botany, v. 51, p.327-32, 1973. 
HERING, M.; PUTZKE, M. T. L. Cattleya, Brassavola and Sophrnitis (Orchidaceae) distribuition and habitat characterization in Estrala Municipality, southern Brazil. Caderno de Pesquisa, v. 19: p. 24-28, 2007.

ICHIHASHI, S. Effects of light on root formation of Bletilla striata seedlings. Lindleyana, v. 5, n. 2, p. 140-143, 1990.

JOHNSON, T. R.; KANE, M. E.; PÉREZ, H. E. Examining the interaction of light, nutrients and carbohydrates on seed germination and early seedling development of Bletia purpurea (Orchidaceae). Plant Growth Regulation. v. 63, p. 89-99, 2011.

KALIMUTHU, K.; SENTHILKUMAR, R.; VIJAYAKUMAR, S. In vitro micropropagation of orchid, Oncidium sp. (Dancing Dolls). African Journal of Biotechnology, v. 6, n. 10, p. 1171-1174, 2007.

KAUTH, P. J.; VENDRAME, W. A.; KANEL, M. E. In vitro seed culture and seedling development of Calopogon tuberosus. Plant Cell, Tissue and Organ Culture, v. 85, p. 91-102, 2006.

KRAUS, J. E.; KERBAUY, G. B.; MONTEIRO, W. R. Desenvolvimento de protocormos de Catasetum pileatum Rchb. f. in vitro: aspectos estruturais e conceituais. Hoehnea, v. 33, n. 2: p. 177-184. 2006.

LEROUX, G.; BARABÉ, D.; VIETH, J. Morphogenèse comparée de protocormes du Cypripedium acaule (Orchidaceae) cultives in vitro avec ou sans sucre. Canadian Journal of Botany, v. 73, p. 1391-1406, 1995.

MANTELL, S. H.; MATTHEWS, J. A.; MCKEE, R. A. Princípios de biotecnologia em plantas: uma introdução à engenharia genética em plantas. Ribeirão Preto: Sociedade Brasileira de Genética, 1994.

MORAES, R. M.; CALDAS, L. S.; SILVEIRA, C. E. S.; SOUZA, A. V.; BERTONI, B. W.; PEREIRA, A. M. S. Micropropagação e banco de germoplasma in vitro para produção e conservação de plantas nativas do Cerrado. In: PEREIRA, A. M. S. (Org.) Recursos genéticos e conservação de plantas medicinais do Cerrado, Ribeirão Preto, SP, Brasil, p. 185-211, 2007.

NIETSCHE, S.; MARQUES, S. V.; PEREIRA, M. C. T.; SALLES, B.; XAVIER, A. A.; FRANÇA, A. C.; LIMA, C.; SILVA, L. S. Estabelecimento in vitro de explantes de três cultivares de bananeira. Ciência Rural, v. 36, n. 3, p. 989-991, 2006.

PEREIRA, O. L.; KASUYA, M. C. M.; ROLlEMBERG, C. L.; BORGES A. C. Indução in vitro da germinação de sementes de Oncidium flexuosum (Orchidaceae) por fungos micorrízicos rizoctonióides. Revista Brasileira de Ciência do Solo, v. 29, p. 199-206, 2005. PINHAL, H. F.; ANASTÁCIO, M. R.; CARNEIRO, P. A. P.; SILVA, V. J.; MORAIS, T. P.; LUZ, J. M. Q. Aplicações da cultura de tecidos vegetais em fruteiras do Cerrado. Ciência Rural, Santa Maria, v. 41, n. 7, p. 1136-1142, jul. 2011.

REED, B. M.; GUPTA, S.; UCHENDU, E. E. In vitro genebanks for preserving tropical biodiversity. In: NORMAH, M. N.; CHIN, H. F.; REED, B. M. (Org.) Conservation of tropical plant species. Nova York: Springer, 2013.

RECH, A. R.; ROSA, Y. B. C. J.; MANENTE-BALESTIERI, F. C. L. Aspects of the reproductive biology of Brassavola cebolleta (Orchidaceae). Acta Scientiarum, v. 32, p. 335-341, 2010. 
RECH, A. R.; ROSA, Y.; BRITO, C. J.; ROSA-JUNIOR, E. J. Levantamento e características ecológicas de Orchidaceae da mata ciliar do Rio Dourados, DouradosMS. Revista Árvore, Viçosa, v. 35, n. 3, p. 717-724, 2011.

SANTOS, I. Criopreservação: potencial e perspectivas para a conservação de germoplasma vegetal. Revista Brasileira de Fisiologia Vegetal, v. 12, p. 70-84, 2000.

SANTOS, G. A.; SAITO, B. C.; MONTEIRO, D. P.; GUTIERRE, M. A. M.; ZONETTI, P. C. Utilização de reguladores hormonais na germinação e formação de plântulas in vitro de orquídeas. Cesumar, v. 9, p. 7-12, 2007.

SANTOS, I. R. I.; SALOMÃO, A. N. Manual de curadores germoplasma-vegetal: criopreservação. Embrapa recursos genéticos e Biotecnologia, 2010.

SANTOS, M. C.; LÉDO, A. S.; LÉDO, C. A. S.; SOUZA, F. V. Efeito da sacarose e do sorbitol na conservação in vitro de segmentos nodais de mangabeira. Revista Ciências Agronomia, v. 42, n. 3, p. 735-741, 2011.

SCHNEIDERS, D.; PESCADOR, R.; BOOZ, M. R.; SUZUKI, R. M. Germinação, crescimento e desenvolvimento in vitro de orquídeas (Cattleya spp., Orchidaceae). Revista Ceres, Viçosa, v. 59, n. 2, p. 185-191, mar./abr. 2012.

SOARES, J. S.; ROSA, Y. B. C. J.; MACEDO, M. C.; SORGATO, J. C.; ROSA, D. B. C. J.; ROSA, C. B. C. J. Cultivo in vitro de Brassavola tuberculata (Orchidaceae) em meio de cultura alternativo suplementado com diferentes concentrações de açúcar e carvão ativado. Magistra v. 24, p. 226-233, 2012.

SOUZA, G. C.; CLEMENTE, P. L.; ISAAC, V. L. R.; FARIA, S. P.; CAMPOS, M. R. C. Contaminação microbiana na propagação in vitro de Cattleya walkeriana e Schomburgkia crispa. Revista Brasileira de Biociências, Porto Alegre, v. 5, supl. 1, p. 405-407, jul. 2007.

THOMAS, P.; SWARNA, G. K.; ROY, P. K.; PATIL, P. Identification of cultureable and originally non-culturable endophytic bacteria isolated from shoot tip cultures of banana cv. Grand Naine. Plant Cell, Tissue and Organ Culture, v. 93, p. 55-63, 2008.

THOMAS, P.; SOLLY, T. Endophytic bacteria associated with growing shoot tips of banana (Musa sp.) cv. grand naine and the affinity of endophytes to the host. Microbial Ecology, v. 58, p. 952-964, 2009.

THOMAS, P.; KUMARI, S. Inconspicuous endophytic bacteria mimicking latex exudates in shoot-tip cultures of papaya. Scientia Horticulturae, v. 124, p. 469-474, 2010.

UNEMOTO, L. K.; FARIA, R. T.; VIEIRA, A. O. S.; DALIO, R. J. D. Propagação in vitro de orquídeas brasileiras em meio de cultura simplificado. Revista Brasileira de Agrociência, Pelotas, v. 13, n. 2, p. 267-269, 2007.

VENDRAME, W.; FARIA, R. T.; SORACE, M.; SAHYUN, S. A. Orchid Cryopreservation. Ciência e Agrotecnologia, Lavras, v. 38, n. 3, p. 213-229, mai./jun. 2014.

VIEIRA, M. L. C.; APEZZATO, B. G. Fundamentos e aplicações da cultura de tecidos no melhoramento. In: NASS, L. L.; VALOIS, A. C. C.; MELO, I. S.; VALADARESINGLIS, M. C. Recursos genéticos e melhoramento. Rondonópolis: Fundação Mato Grosso, 2001. 